\title{
EVIDÊNCIAS DA INTEGRAÇÃO PRODUTIVA ENTRE BRASIL E ARGENTINA NO CONTEXTO DO MERCOSUL (1993-2019)^
}

\author{
(1993-2019) \\ Thiago P. de A Cavalcante* \\ Marcelo Milan** \\ Henrique Morrone***
}

EVIDENCES OF PRODUCTIVE INTEGRATION BETWEEN BRAZIL AND ARGENTINA IN THE MERCOSUR CONTEXT

enviado: 19 noviembre 2020 - aprobado: 06 mayo 2021

\begin{abstract}
Resumo
As iniciativas de integração regional proporcionam a oportunidade de integrar as estruturas produtivas dos países envolvidos, buscando a exploração de economias de escala e atividades de maior valor agregado. Este artigo tem como objetivo mensurar o avanço da integração produtiva entre Brasil e Argentina, no sentido de averiguar se este fenômeno foi favorecido pela formação do Mercosul. A metodologia utilizada baseia-se em indicadores de participação do comércio intraindustrial e da incidência do intercâmbio de bens intermediários. Os resultados revelam crescimento limitado e movimentos instáveis dos indicadores de integração produtiva. As evidências sugerem que a contribuição de uma integração regional na promoção da
\end{abstract}

Cavalcante, T. P. A., Milan, M., \& Morrone, H. (2022). Evidências da integração produtiva entre Brasil e Argentina no contexto do Mercosul (1993-2019). Estudios económicos, 39(78), pp. 157-186. DOI: https://doi.org/10.52292/j.estudecon.2022.2274

* Instituto Federal do Maranhão (IFMA), Brazil. ORCID: https://orcid.org/0000-0002-0033-513X. E-mail: tpacavalcante@riseup.net.

** Universidade Federal do Rio Grande do Sul (UFRGS), Brazil. ORCID: http://orcid.org/0000-00017586-6528. E-mail: milan.econ@gmail.com

*** Universidade Federal do Rio Grande do Sul (UFRGS), Brazil. ORCID: http://orcid.org/0000-00019579-8489 E-mail: hmorrone@hotmail.com 
integração produtiva será maior à medida que mais eficientes e sustentadas forem as políticas voltadas para esse objetivo.

Palavras-chave: comércio intraindustrial, fragmentação internacional da produção, Integração regional, integração produtiva, Mercosul.

Classificação JEL: F14, F15.

\begin{abstract}
Regional integration initiatives provide the opportunity to integrate the productive structures of the countries involved, seeking to explore economies of scale and activities with greater added value. This article aims to measure the progress of productive integration between Brazil and Argentina, in order to ascertain whether this phenomenon was favored by the formation of Mercosur. The methodology used is based on indicators of participation of intra-industrial trade and in the incidence of the exchange of intermediate goods. The results reveal limited growth and unstable movements in the productive integration indicators. Evidence suggests that the contribution of regional integration to promoting the productive integration of its members will be greater the more efficient and sustained are the policies aimed at this objective.
\end{abstract}

Keywords: international fragmentation of production, intra-industrial trade, Mercosur, productive integration, regional integration.

JEL Codes: F14, F15. 


\section{INTRODUÇÃO}

Surgiu nos anos 1990 uma segunda onda de regionalismo, conhecida como regionalismo aberto, a partir da intensificação da globalização, aceleração da economia global e o fim da Guerra Fria (1947-1991) (Mansfield \& Milner, 1999). Seu objetivo é promover uma melhor inserção econômica internacional dos membros baseada na percepção de que este movimento é inevitável. A integração regional deveria se concentrar principalmente, portanto, em criar as melhores condições para este processo. "O que se busca com o regionalismo aberto é que as políticas explícitas de integração sejam compatíveis com as políticas tendentes a elevar a competitividade internacional, além de complementares entre elas" (Comissão Econômica para a América Latina [CEPAL], 2000b, p. 945).

Ferrer (2006) sustenta que um dos dilemas na trajetória de desenvolvimento econômico dos países periféricos é a sua inserção internacional, para a qual os processos de integração regional são importantes condicionantes. No âmbito de uma iniciativa de integração regional mais profunda, espera-se que os países membros unam forças políticas no sentido de promover uma integração produtiva regional com um caráter econômico mais complexo, de modo que possa participar de etapas produtivas de maior valor agregado ao se inserir nas cadeias globais de valor. Assim, estas iniciativas representam oportunidades para promover uma integração produtiva comprometida com os objetivos do projeto de desenvolvimento econômico regional (Comissão Econômica para a América Latina [CEPAL], 2000a).

O Mercado Comum do Sul (Mercosul) se formou exatamente neste contexto, em 1991, e influenciado por estas ideias. Ele é fruto das negociações originalmente entre os presidentes da Argentina e do Brasil nos anos 1980, respectivamente Raúl Alfonsín e José Sarney. Em 1988 estes dois países assinaram o Tratado de Integração, Cooperação e Desenvolvimento (1988) que previa a construção de um espaço econômico comum e a coordenação das políticas econômicas e industriais. O processo de integração entre eles continuaria avançando, porém, a partir do início da década de 1990, assumiria outras características. Criado a partir do Tratado de Assunção (1991), o Mercosul manteve no seu tratado de formação os mesmos ideais pensados inicialmente, inclusive com referência à complementação dos diferentes setores da economia para atingir seu objetivo maior: acelerar o processo de desenvolvimento com justiça social (Mercado Comum do Sul [MERCOSUL], 1991). Objetivamente, no entanto, se consolidou como uma integração regional de baixa institucionalidade e estabeleceu como meta criar uma área de livre comércio e desenvolver a competitividade das empresas da região de capital local ou estrangeiro (Bandeira, 2010). O Mercosul, na prática, seria uma plataforma para conso- 
lidar a inserção político-econômica dos países membros no âmbito internacional com base nas vantagens comparativas (Vigevani \& Mariano, 2001).

De qualquer maneira, o Mercosul possibilita a coordenação de esforços capazes de promover um desenvolvimento industrial conjunto, que contemple a formação ou consolidação de especializações produtivas intrassetoriais. Assim, este artigo tem como objetivo mensurar o avanço da integração produtiva entre os dois principais membros do Mercosul, Brasil e Argentina, no sentido de averiguar se este fenômeno foi favorecido pela formação do bloco econômico. Para isso, utilizaremos metodologias empíricas de comércio internacional e índice de importância relativa do comércio de partes e componentes, apresentadas com mais detalhes na seção metodológica.

A hipótese básica de trabalho é a de que avanços consistentes na integração produtiva entre Brasil e Argentina revelariam a contribuição do Mercosul em reestruturar a estrutura produtiva regional e promover uma melhor inserção internacional dos seus membros. Por outro lado, caso este avanço econômico-produtivo não tenha sido alcançado, é sinal de que este modelo de integração foi insuficiente em alcançar um dos seus mais importantes objetivos.

Além desta introdução, este artigo está composto por mais três seções além das considerações finais. A seção seguinte apresenta o referencial teórico sobre a fragmentação internacional da produção. A terceira seção apresenta a metodologia. A análise dos resultados obtidos é efetuada na quarta seção. A quinta seção apresenta as considerações finais.

\section{FRAGMENTAÇÃO E INTEGRAÇÃO PRODUTIVAS}

Na segunda metade do século XX, notadamente a partir da década de 1970, o fenômeno da fragmentação internacional da produção começou a ser observado com mais intensidade e trouxe consigo mudanças na divisão internacional do trabalho e, consequentemente, no caráter do comércio (Baldwin, 2012; Carneiro, 2015).

Na medida em que a concorrência intercapitalista se intensificou e a produção industrial se tornou mais complexa, demandando maiores volumes de investimentos, as empresas nacionais menores foram gradativamente incorporadas às maiores. Este processo sistemático de concentração e centralização do capital conferiu às grandes empresas multinacionais (EMNs) um papel cada vez maior na distribuição geográfica da produção. Nos anos 1970 teria começado uma nova divisão 
internacional do trabalho, motivada pela chamada reestruturação empresarial e a intensificação dos investimentos diretos no exterior, com o objetivo de conquistar novos mercados e obter menores custos de produção (Chesnais, 2013; Milberg \& Winkler, 2013). O resultado foi a distribuição de várias etapas dos processos produtivos para as economias periféricas e semiperiféricas, que dispunham de razoável infraestrutura e baixo custo de mão de obra (Park, Nayyar \& Low, 2013).

Uma consequência importante deste rearranjo produtivo internacional foi a modificação do caráter do comércio internacional. Até meados do século XX ele se dava nos moldes da tese das vantagens comparativas desenvolvida por Ricardo (1996) em 1817 e aprimorada no modelo de Ohlin (1933). A tese de Ricardo sustentava que haveria ganhos mútuos caso os diversos países se especializassem na produção dos bens em que fossem relativamente mais eficientes e adquirissem os demais por meio do comércio. A tese das vantagens comparativas deduz um padrão de comércio interindustrial, no qual os países importam produtos de ramos industriais diferentes daqueles que exportam.

Este padrão de comércio gerou o que Findlay e O'Rourke (2007) denominaram de a grande especialização e teria ocorrido a partir do final do século XVIII e até a Segunda Guerra Mundial (1939-1945). No pós-guerra se observou um ponto de inflexão no sentido do aumento da proporção de comércio intraindustrial (CII), isto é, do intercâmbio de bens do mesmo ramo industrial. O fenômeno de um mesmo país exportar e importar bens de um mesmo ramo industrial era novo na teoria econômica e inconsistente com as conclusões da teoria convencional do comércio internacional (Grubel \& Lloyd, 1975).

Na tese das vantagens comparativas e no modelo Heckscher-Ohlin, o comércio internacional era explicado a partir das dotações de fatores de produção entre os países a qual, no limite, definiriam o bem que um dado país produziria de forma mais eficiente. No entanto, os retornos crescentes de escala eram o elemento fundamental para explicar o CII que se observara na época, mas que era negligenciado pela teoria convencional porque "[...] it has appeared difficult to deal with the implications of increasing returns for market structure" (Krugman, 1979, p. 469).

No seu artigo de 1979, Krugman se propôs precisamente a desenvolver um modelo de comércio internacional no qual a economia de escala jogasse um papel decisivo. Krugman argumentou que a teoria convencional do comércio era incapaz de entender o recente surgimento do CII porque desconsiderava a (1) demanda dos indivíduos por variedades de um mesmo produto e (2) o rendimento crescente de escala. Desta forma, concluiu que o comércio internacional não é um resultado 
apenas das diferenças de dotações de fatores e tecnologia, mas, ao invés disso, "[...] trade may simply be a way of extending the market and allowing exploitation of scale economies, with the effects of trade being similar to those of labor force growth and regional agglomeration" (Krugman, 1979, p. 479).

O CII pode ser do tipo horizontal ou vertical a depender da forma em que estes bens se diferenciam, respectivamente, por variedades ou qualidades. A fragmentação da produção está mais relacionada com este segundo tipo porque pressupõe o intercâmbio de partes e componentes, bens intermediários em geral, de diferentes etapas produtivas que apresentam diferentes qualidades e níveis de valor adicionado (Organização para Cooperação e Desenvolvimento Econômico [OCDE], 2002; Flôres Junior, 2010; Nonnenberg, 2013). Assim, a reunião destes produtos para a montagem do bem final produz principalmente CII vertical.

A fragmentação internacional da produção foi conduzida fundamentalmente a partir das EMNs na sua tomada de decisão por uma separação e realocação de suas atividades, em detrimento da verticalização produtiva. A partir da década de 1970, o CII ganhou força com o movimento das EMNs de dispersar internacionalmente muitas das suas etapas produtivas e se concentrando naquelas consideradas centrais, como a pesquisa e desenvolvimento $\mathrm{P} \& \mathrm{D}$ e a valorização da sua própria marca (Chesnais, 1996; Carneiro, 2015).

Este fenômeno foi produto da superação do paradigma fordista de organização industrial, baseada na produção em massa verticalmente integrada, e no desenvolvimento do novo paradigma denominado pós-fordista, no qual a eficiência produtiva baseou-se na ideia de flexibilidade e na articulação entre empresas e outsourcing, isto é, na distribuição das etapas produtivas entre elas (Milberg \& Winkler, 2013). O objetivo desta reorganização empresarial interna era explorar vantagens comparativas, como baixos custos de mão de obra, disponibilidade de insumos e recursos naturais, entre outros. As EMNs não só distribuíram suas atividades para outras empresas, por meio do outsourcing, como também o fizeram para outros países, processo conhecido na literatura como offshoring. $\mathrm{O}$ elemento novo deste período foi a combinação de ambos, gerando verdadeiras cadeias globais de valor (Nonnenberg, 2013; Park, Nayyar \& Low, 2013; Carneiro, 2015).

Baldwin (2012) analisa as CGVs de uma perspectiva histórica e argumenta que a globalização é um fenômeno que vem se desenvolvendo há pelo menos três séculos. A fragmentação internacional da produção precisou de dois conectivos tecnológicos para acontecer, chamados pelo autor de two unbundlings. O primeiro processo de desagregação se deu ainda no século XIX com a revolução do vapor, 
que, a partir da produção de trens e navios a vapor, tornou possível separar geograficamente a produção do consumo, o que garantiu a exploração de economias de escala e reforçou a divisão internacional do trabalho com base na tese das vantagens comparativas.

Porém, "[...] the first unbundling did not make the world flat. Indeed, it produced the first globalization paradox: freer trade led production to cluster locally in factories and industrial districts" (Baldwin, 2012, p. 3). De fato, elevações significativas da escala de produção geram um aumento de complexidade da planta industrial e dos custos de coordenação. Por estas razões, observou-se com a revolução do vapor um movimento no sentido da formação de clusters industriais, ou seja, da concentração geográfica da produção industrial.

Este fenômeno se reverteu apenas com o segundo processo de desagregação (second unbundling, nas palavras do autor), isto é, com o desenvolvimento das tecnologias da informação e comunicação (TICs) que facilitaram a coordenação entre plantas produtivas geograficamente dispersas e criaram as bases para a exploração do diferencial do custo da mão de obra entre os países desenvolvidos e em desenvolvimento através do offshoring e outsourcing. Como resultado, formaram-se cadeias globais de valor, que, do ponto de vista comercial, implicaram na intensificação do CII de bens intermediários.

Paradoxalmente, a integração produtiva entre os países aparece como produto do fenômeno mencionado, isto é, da iniciativa das EMNs em fragmentar a produção criando cadeias de valor, ou seja, integrando os mais diversos países a partir do processo produtivo de um determinado bem. Machado (2010) destaca que este processo é mais que a simples desverticalização da produção em diversas empresas, localizada em vários países, na qual o suprimento passaria por uma simples relação de compra e venda no mercado. A integração produtiva implica o desenvolvimento de redes complexas de suprimento e governança, legitimadas por contratos de fornecimento entre as empresas presentes na cadeia de valor.

\section{METODOLOGIA}

Na medida em que o fenômeno da fragmentação da produção foi percebido e começou a ser estudado, várias metodologias da sua mensuração foram propostas. As análises empíricas concentram esforços majoritariamente nos fluxos comerciais, visando identificar o intercâmbio de bens intermediários e a incidência do CII. As subseções a seguir apresentam os principais indicadores utilizados. 


\section{II.1. Índices de comércio intraindustrial}

Grubel e Lloyd (1975) desenvolveram uma metodologia do CII, conhecida como índice Grubel-Lloyd (GL), que representa o primeiro grande avanço na área e um dos índices mais utilizados na comunidade acadêmica. O CII é também um produto da agregação estatística, e o esforço dos pesquisadores nesse momento consistia em desenvolver metodologias para identificar especializações intraindustriais a partir de dados estatísticos suficientemente desagregados (Grubel \& Lloyd, 1975).

O fluxo comercial de bens inseridos no mesmo ramo industrial pode estar estatisticamente registrado na mesma nomenclatura, dependendo do nível de agregação dos dados, porém, isto não indica compra e venda do mesmo bem por um determinado país. De fato, bens tão distintos quanto à complexidade e ao valor agregado como canoas e navios podem estar inseridos no mesmo ramo industrial (navios, barcos e outras estruturas flutuantes, referente ao código 793 do SITC). Neste caso, um país poderia estar importando navios e exportando canoas, enquanto ambos os valores estariam registrados na mesma nomenclatura do fluxo comercial. Por princípio, importações e exportações de bens na mesma nomenclatura estatística devem consistir em produtos diferentes, seja conforme a aparência, sofisticação tecnológica, durabilidade ou em outras características.

O primeiro passo para a análise do CII é a definição de indústria. Para os objetivos do índice, a indústria foi definida de forma pragmática como uma nomenclatura do SITC para um dado nível de agregação. Por exemplo, todos os dados de comércio referentes aos produtos químicos orgânicos, código 51 a dois dígitos de agregação do SITC, são considerados comércio da indústria de produtos químicos orgânicos. Da mesma forma para o fluxo comercial dos produtos da indústria de couro, inseridos no código 611 a três dígitos de agregação do SITC.

O CII, portanto, é calculado a partir do fluxo de comércio, exportações (X) e importações (M), de bens de uma determinada indústria i. Se o comércio do país A de bens da indústria i é apenas em um sentido (apenas exportações ou apenas importações) este comércio é considerado interindustrial. O índice Grubel-Lloyd captura o total do CII como parcela do comércio total de todas as indústrias (Grubel \& Lloyd, 1975):

$$
G L_{i}=\frac{\sum_{i}^{n}\left(X_{i}+M_{i}\right)-\sum_{i}^{n}\left|X_{i}-M_{i}\right|}{\sum_{i}^{n}\left(X_{i}+M_{i}\right)-\left|\sum_{i}^{n} X_{i}-\sum_{i}^{n} M_{i}\right|} * 100
$$


O trabalho de Fontagné e Freudenberg (1997) representa mais um avanço no debate sobre metodologias de mensuração do CII. Este trabalho partiu das contribuições mais recentes deste fenômeno, como a compreensão de que os produtos de um mesmo ramo industrial podem se diferenciar quanto à variedade (horizontal) e quanto à qualidade (vertical) (Lancaster, 1979).

Além disso, os autores estavam insatisfeitos com o problema da dupla explicação do fluxo majoritário do comércio bilateral presente no índice GL. Para Grubel e Lloyd (1975), apenas o solapamento comercial dos fluxos de bens de uma determinada indústria é considerado comércio intraindustrial. A diferença, portanto, é considerada comércio interindustrial. Desta forma, parte do fluxo majoritário é explicada pela nova abordagem do comércio internacional, com base na concorrência imperfeita, e a outra parte é explicada pela teoria convencional baseada na concorrência perfeita. Portanto, tem-se uma dupla explicação da natureza do fluxo comercial de um mesmo bem.

A metodologia proposta por Fontagné e Freudenberg (1997) evita este problema incorporando uma condição, baseada na proporção do solapamento comercial, para caracterizar as exportações e importações totais de bens do mesmo ramo industrial como sendo apenas intraindustrial ou interindustrial. Além disso, o índice FF caracteriza o comércio bilateral total em três partes: comércio intraindustrial de produtos diferenciados horizontalmente, comércio intraindustrial de produtos diferenciados verticalmente e comércio interindustrial.

Para determinar se os produtos registrados no mesmo ramo industrial são diferenciados por variedades ou qualidades, os autores consideram as diferenças no seu preço unitário. Eles assumiram que se os valores unitários, digamos, das exportações são superiores aos das importações em mais de 15\%, então estes produtos apresentam qualidades distintas, portanto se trata de um CII de produtos diferenciados verticalmente. Se a diferença dos preços unitários é de até $15 \%$, então se trata de produtos diferenciados horizontalmente. Esta condição pode ser expressa da seguinte forma:

$$
\frac{1}{1.15} \leq \frac{U V_{k k^{\prime} i t}^{X}}{U V_{k k^{\prime} i t}^{M}} \leq 1.15
$$

Onde UV se refere ao valor unitário dos produtos, $\mathrm{X}$ indica exportação, $\mathrm{M}$ importação, k é o país de análise, k’ é o seu parceiro comercial, i é o produto e t o ano. 
Fontagné e Freudenberg (1997) estabeleceram que o intercâmbio de uma determinada indústria só será considerado intraindustrial, portanto de duas vias, se o menor fluxo (exportação ou importação) representar mais de $10 \%$ do fluxo maior. Caso contrário o nível de solapamento é considerado insignificante e o intercâmbio será classificado como interindustrial, ou seja, de via única. Algebricamente esta condição pode ser escrita da seguinte forma:

$$
\frac{\operatorname{Min}\left(X_{k k^{\prime} i t^{\prime}} M_{k k^{\prime} i t}\right)}{\operatorname{Max}\left(X_{k k^{\prime} i t^{\prime}} M_{k k^{\prime} i t}\right)}>10 \%
$$

Estas duas condições definem os três tipos de comércio bilaterais possíveis para um determinado ano. Se, de acordo com a segunda condição, o fluxo comercial de uma determinada indústria for considerado de via única, tem-se o comércio interindustrial. Caso seja considerado de via dupla, portanto intraindustrial, a primeira condição definirá se os produtos são diferenciados horizontalmente ou verticalmente.

Mais recentemente foi proposta uma decomposição do fluxo CII vertical em dois tipos, de acordo com a diferença de qualidades (Angelis \& Porta, 2014). Da forma originalmente proposta, o índice FF poderia captar as exportações de canoas e importações de navios como sendo um fluxo de CII vertical, sem fazer nenhuma qualificação sobre quem vende e quem compra o produto de maior valor unitário. Neste caso, realiza-se uma nova comparação dos preços unitários dos produtos classificados como verticalmente diferenciados. O fluxo comercial será caracterizado como CII vertical de alta gama nos casos em que o país exportar o maior valor unitário, e de baixa gama quando exportar o menor valor unitário. Para isto, basta observar a condição abaixo que, se for verdadeira, indica que se trata de alta gama.

$$
\frac{U V X}{U V M}>1.15
$$

Onde UVX é o valor unitário das exportações e UVM o valor unitário das importações dos produtos das indústrias já identificadas no CII vertical. Com isso, tem-se uma decomposição do fluxo comercial em quatro partes:

- Comércio intraindustrial de produtos diferenciados horizontalmente (CIIH).

- Comércio intraindustrial de produtos diferenciados verticalmente de alta gama (CIIVA). 
- Comércio intraindustrial de produtos diferenciados verticalmente de baixa gama (CIIVB).

- Comércio interindustrial.

É importante destacar que os índices GL e FF são mais complementares do que substitutos. Fontagné e Freudenberg (1997) argumentam que o primeiro tem o objetivo maior de mensurar a magnitude do solapamento comercial entre dois países, enquanto o segundo índice é mais apropriado para medir a importância relativa de cada tipo de fluxo comercial.

\section{II.2. Importância relativa do comércio de partes e componentes}

O CII consiste numa evidência importante de integração produtiva entre os países. No entanto, por vezes isto pode significar apenas o intercâmbio entre bens finais de qualidades ou variedades distintas. A integração produtiva implica o intercâmbio de bens intermediários, que compõem os fluxos intraindustriais, mas que não consistem necessariamente na sua totalidade. Portanto, outros níveis de investigação são necessários para compreender com mais precisão a relação econômica existente entre os países analisados.

Preocupado com o fenômeno da fragmentação internacional da produção, em que diferentes estágios produtivos de um mesmo bem são localizados em mais de um país, Yeats (1998) foi um dos primeiros autores a publicar um trabalho dedicado a investigar a importância relativa do comércio de partes e componentes (IRPC). Porém, antes da publicação da segunda revisão do Standard International Trade Classification (SITC) ${ }^{1}$, em 1975, não era possível identificar nos dados do fluxo comercial o que se referia ao intercâmbio de partes e componentes e outros bens intermediários. Com esta revisão do SITC, o sistema de classificação incluiu uma seção (SITC 7) referente a máquinas e equipamento de transportes, que abarca a maior parte dos fluxos de bens intermediários de uma cadeia produtiva, além de alguns bens finais.

A partir das subsequentes revisões do sistema de classificação SITC $^{2}$, novas subdivisões dos bens intermediários foram criadas. No momento do trabalho de Yeats (1998), que coletou dados para os anos de 1978, 1985, 1990 e 1995, o SITC

1 É o sistema da Organização das Nações Unidas (ONU) de classificação dos produtos comercializados entre países.

2 A edição atual é a revisão 4, publicada em 2006. 
contava com 44 nomenclaturas a respeito do comércio de partes e componentes. A terceira revisão do SITC desagregou ainda mais estas informações e apresentou 83 nomenclaturas. Isto abre novas possibilidades de análise porque mais informação pode ser extraída dos dados.

Flôres Junior (2010) argumenta que no caso dos países latino-americanos, em que não existe uma variedade de dados tão ampla, é possível adaptar esta metodologia e incluir na análise não só o comércio de partes e componentes, mas também os bens considerados semiacabados. Isto porque os bens semiacabados também são incorporados como insumo das indústrias e nem todos fazem parte do grupo 7 do SITC e, além disso, determinados estágios de produção utilizam, inclusive, mais os bens semiacabados como insumo do que as peças e componentes. No entanto, esta categoria de bens precisa ser analisada com cautela, já que inclui muitas commodities e derivados de recursos naturais apenas levemente elaborados.

Quadro 1. Correspondência entre os Estágios de Produção e os Códigos BEC

\begin{tabular}{|c|c|c|c|}
\hline \multicolumn{2}{|c|}{ Estágio de Produção } & $\begin{array}{l}\text { Código } \\
\text { BEC }\end{array}$ & Descrição BEC \\
\hline \multirow{3}{*}{\multicolumn{2}{|c|}{ Bens Primários (I) }} & 111 & $\begin{array}{l}\text { Alimentos e bebidas básicos, destinados } \\
\text { principalmente à indústria }\end{array}$ \\
\hline & & 21 & Insumos industriais básicos \\
\hline & & 31 & Combustíveis e lubrificantes básicos \\
\hline \multirow{6}{*}{$\begin{array}{l}\text { Bens } \\
\text { Intermediários }\end{array}$} & \multirow{4}{*}{$\begin{array}{c}\text { Bens } \\
\text { Semiacabados } \\
\text { (II) }\end{array}$} & 121 & $\begin{array}{l}\text { Alimentos e bebidas elaborados, } \\
\text { destinados principalmente à indústria }\end{array}$ \\
\hline & & 22 & Insumos industriais elaborados \\
\hline & & 321 & $\begin{array}{l}\text { Combustíveis e lubrificantes elaborados - } \\
\text { carburantes }\end{array}$ \\
\hline & & 322 & $\begin{array}{l}\text { Outros combustíveis e lubrificantes } \\
\text { elaborados }\end{array}$ \\
\hline & \multirow{2}{*}{$\begin{array}{c}\text { Partes e } \\
\text { Componentes } \\
\text { (III) }\end{array}$} & 42 & Peças e acessórios para bens de capital \\
\hline & & 53 & Peças para equipamentos de transporte \\
\hline
\end{tabular}




\begin{tabular}{|c|c|c|c|}
\hline \multirow{9}{*}{ Bens Finais } & \multirow{2}{*}{$\begin{array}{c}\text { Bens de } \\
\text { Capital (IV) }\end{array}$} & 41 & $\begin{array}{l}\text { Bens de capital (exceto equipamentos de } \\
\text { transporte) }\end{array}$ \\
\hline & & 521 & Equipamento de transporte industrial \\
\hline & \multirow{7}{*}{$\begin{array}{c}\text { Bens de } \\
\text { Consumo (V) }\end{array}$} & 112 & $\begin{array}{l}\text { Alimentos e bebidas básicos, destinados } \\
\text { principalmente ao consumo doméstico }\end{array}$ \\
\hline & & 122 & $\begin{array}{l}\text { Alimentos e bebidas elaborados, } \\
\text { destinados principalmente ao consumo } \\
\text { doméstico }\end{array}$ \\
\hline & & 51 & Veículos automotores de passageiros \\
\hline & & 522 & Equipamento de transporte não industrial \\
\hline & & 61 & Bens de consumo duráveis \\
\hline & & 62 & Bens de consumo semiduráveis \\
\hline & & 63 & Bens de consumo não duráveis \\
\hline
\end{tabular}

Fonte: Flôres Júnior (2010, p. 77)

Para identificar o estágio de produção dos dados do SITC, é necessário reclassificá-los com base no seu uso a partir do sistema Broad Economic Categories (BEC). Lemoine e Unal-Kesenci (2004) propuseram uma classificação em três estágios de produção dos códigos do BEC: (a) bens primários (I); (b) bens intermediários e (c) bens finais. $\mathrm{O}$ grupo (b) pode ser dividido em duas categorias, bens semiacabados (II) e partes e componentes (III); enquanto o grupo (c) se divide em bens de capital (IV) e bens de consumo (V). O Quadro 1 sistematiza esta classificação.

O passo seguinte é observar a correspondência entre os códigos do BEC e do SITC para distinguir o conteúdo do comércio bilateral entre as cinco categorias definidas. Esta tarefa pode ser feita com base nas tabelas de correspondência entre os vários sistemas de classificação do comércio internacional, disponibilizados pelo departamento de estatísticas das Nações Unidas.

Uma limitação importante desta metodologia, conforme sustenta Carneiro (2015), é que o estágio de produção dos bens é definido em função do seu uso principal, que é determinado pela sua natureza e não pelo seu uso efetivo. Tratase de um detalhe relevante porque muitos produtos podem ser utilizados tanto no processo produtivo quanto como bens finais, como é o caso dos combustíveis. 


\section{II.3. Estratégia empírica}

Utilizaremos como estratégia empírica deste trabalho uma investigação sobre o caráter e o conteúdo dos fluxos comerciais entre Brasil e Argentina. O primeiro caso visa identificar a evolução da participação do CII em detrimento do comércio interindustrial. Para isso, utilizaremos os índices GL e FF. No segundo caso, a proposta é mensurar a participação do intercâmbio de bens intermediários.

Fontagné e Freudenberg (1997) sustentam que o ideal é utilizar dados com o maior nível de desagregação possível no cálculo dos índices de CII. No entanto, Grubel e Lloyd (1971) argumentam que os dados a 3 dígitos de desagregação do SITC Rev. 3 se assemelham à ideia real de indústria. Portanto, estimamos o índice GL a partir da equação ajustada em dois níveis de agregação: a 3 dígitos a partir dos dados do SITC Rev. 3 e a 6 dígitos com os dados do Harmonized System (HS). O índice FF foi calculado com base nos dados a 6 dígitos do HS. Foi utilizado o limite de ao menos $10 \%$ de solapamento para caracterizar um CII em cada indústria e o de $15 \%$ nos preços unitários para caracterizar produtos diferenciados verticalmente, conforme sugestões originais de Fontagné e Freudenberg (1997). Finalmente, o IRPC foi calculado conforme a classificação proposta por Lemoine e Ünal-Kesenci (2004). A compatibilidade entre os sistemas BEC e o SITC Rev. 3 foi feita com base nas tabelas de correspondências disponibilizadas pelo departamento de estatística das Nações Unidas.

As estimações foram realizadas respeitando intervalos de cinco anos a partir do início dos anos 1990, quando o Mercosul foi criado, até o presente. Começamos em 1993 por questões de incompatibilidade dos dados de comércio internacional em 1991. A expectativa é que os resultados de 1993 ilustrem o estágio inicial da relação econômico-comercial entre os membros do Mercosul. O ano seguinte é 1998, que reflete um momento de forte crescimento do comércio intra-Mercosul, antes de regredir em função da crise econômica argentina (1999-2001) e dos efeitos na região da quebra de paridade do real com o dólar. $\mathrm{O}$ ano de 2003 ainda reflete os efeitos deste contexto de turbulência econômica, no qual o comércio regional foi fortemente prejudicado e seu valor total ainda é inferior aos níveis de 1998. A partir de 2003, o comércio volta a crescer, trajetória que persiste até 2008 , quando se observa novamente um recuo em função da crise financeira internacional (20082009). A partir de 2008, a economia internacional é afetada pela crise financeira, embora alguns países em desenvolvimento, inclusive o Brasil, demoraram um pouco mais para sentir seus efeitos. Em 2013 os níveis de comércio regional se mantêm relativamente estáveis, inclusive apresentando um pequeno crescimento em relação a 2008. No entanto, a partir de 2014, observa-se um novo recuo em 
função do baixo crescimento econômico generalizado em escala global, desta vez, inclusive, brasileiro e argentino, e da crise cambial entre os emergentes, provocada pela apreciação do dólar e da expectativa de elevação da taxa de juros nos Estados Unidos. O ano seguinte, respeitando o intervalo de 5 anos, é o de 2018, que ainda reflete esta conjuntura. Optamos também por incluir o ano de 2019 por ser o primeiro ano do novo governo brasileiro, o do presidente Jair Bolsonaro.

\section{ANÁLISE DE RESULTADOS}

A Tabela 1 agrega os resultados dos índices de CII entre Brasil e Argentina. Naturalmente, os valores são diferentes a depender do nível de agregação e da metodologia utilizada. Porém, o comportamento ao longo do tempo entre as três estimações é semelhante, com correlação de mais de $90 \%$ entre elas. Os resultados confirmam o padrão observado por Lucángeli (2007) e Angelis e Porta (2014) de ganhos de participação do comércio do tipo intraindustrial entre Brasil e Argentina, apesar do recuo conjuntural no final dos anos 1990, captado com os nossos resultados para o ano de 2003. De acordo com o índice GL a 3 dígitos, o comércio bilateral se torna majoritariamente intraindustrial a partir de 2008, com mais de $60 \%$ de participação. Esta mesma metodologia com dados a 6 dígitos revela uma dominância mais acentuada do comércio interindustrial ao longo de todo o período, apesar de o índice ter subido significativamente a partir de 2008. As estimações com base na abordagem de Fontagné e Freudenberg (1997), com dados também a 6 dígitos, acusam uma participação maior do CII comparado com o índice GL, com dados no mesmo nível de agregação. Neste caso, o índice FF registra, inclusive, o CII como majoritário a partir de 2013. Assim, independentemente da metodologia, observa-se um crescimento importante da participação do CII entre Brasil e Argentina nos anos 2000. A reversão desta tendência começa a ser observada a partir dos dados de 2018. Em 2019, inclusive, os números são semelhantes aos do início dos anos 1990.

A composição do CII foi medida a partir do índice FF. Até 2003, a variação do CII foi acompanhada proporcionalmente pelos fluxos horizontal e vertical. Bembi et al. (2012) e Angelis e Porta (2014) identificaram um crescimento importante do CII, explicado, principalmente, com ganhos de participação do CII vertical e uma certa estabilidade do fluxo CII horizontal. Nossos resultados apontam uma perda significativa de participação do fluxo CII horizontal a partir de 2008, até alcançar sua medida mínima em 2019. Ao mesmo tempo, observa-se um cresci- 
mento mais intenso que o destes autores ${ }^{3}$ do CII de produtos diferenciados verticalmente. Finalmente, da parcela do CII classificado como vertical, a maior parte das exportações brasileiras apresenta menor valor unitário. Esta situação se intensifica a partir de 2008 e registra quase $42 \%$ de CIIVB em 2013. Da mesma forma, os resultados de 2018 e 2019 ilustram uma reversão deste quadro no sentido do ganho de participação do comércio interindustrial.

Em 1993 o Brasil já apresentava uma participação considerável de CII com a Argentina, que foi medida em quase $41 \%$ com base no índice GL, com dados a 3 dígitos, e $27 \%$ com base no índice FF, com dados a 6 dígitos. Naquele ano, o CII do tipo vertical (somando os fluxos CIIVA e CIIVB), que está mais relacionado com a integração produtiva, já era maior que o do tipo horizontal.

Supõe-se que os resultados de 1998 já estão significativamente influenciados pela integração regional do Mercosul, principalmente por causa da aproximação política entre os países e pelos primeiros resultados do esforço de eliminação ou redução das tarifas alfandegárias do período de transição (1991-1994). Vale destacar que neste ano o comércio entre Brasil e Argentina quase triplicou em relação ao observado em 1993. Nos anos 1990 não havia nenhuma política explícita em direção à integração produtiva, pois a prioridade naquele contexto era eliminar as barreiras alfandegárias e impulsionar a integração comercial entre os membros. Porém, surpreendentemente os índices de CII subiram significativamente em 1998, a ponto de representar quase metade do comércio bilateral total, $42.85 \%$ de acordo com a medição do índice $\mathrm{FF}$ a 6 dígitos.

Ao examinar os fluxos comerciais desagregados, através da metodologia de Fontagné e Freudenberg (1997), observa-se, em 1998, que a perda de participação do comércio interindustrial foi acompanhada de um ganho equilibrado entre os três tipos de CII, o que sugere que a mudança neste primeiro momento foi apenas quantitativa. Ou seja, provavelmente o contexto de liberalização comercial impulsionou o comércio daqueles setores que já se relacionavam com o país vizinho.

Em termos absolutos, o CII vertical em 1993 somou US\$ 1 bilhão, enquanto em 1998 a cifra alcançou o valor de US\$ 3.8 bilhões. É interessante observar que enquanto o índice de CII vertical cresceu $8.54 \%$ neste período, o valor transacionado deste tipo de fluxo aumentou quase quatro vezes devido ao crescimento do comércio

3 Esta diferença se deve provavelmente ao fato de utilizarmos os fluxos de importação de ambos os lados para calcular os índices. Desta forma, o valor do comércio total se altera gerando impacto direto no cálculo do valor unitário dos produtos. 


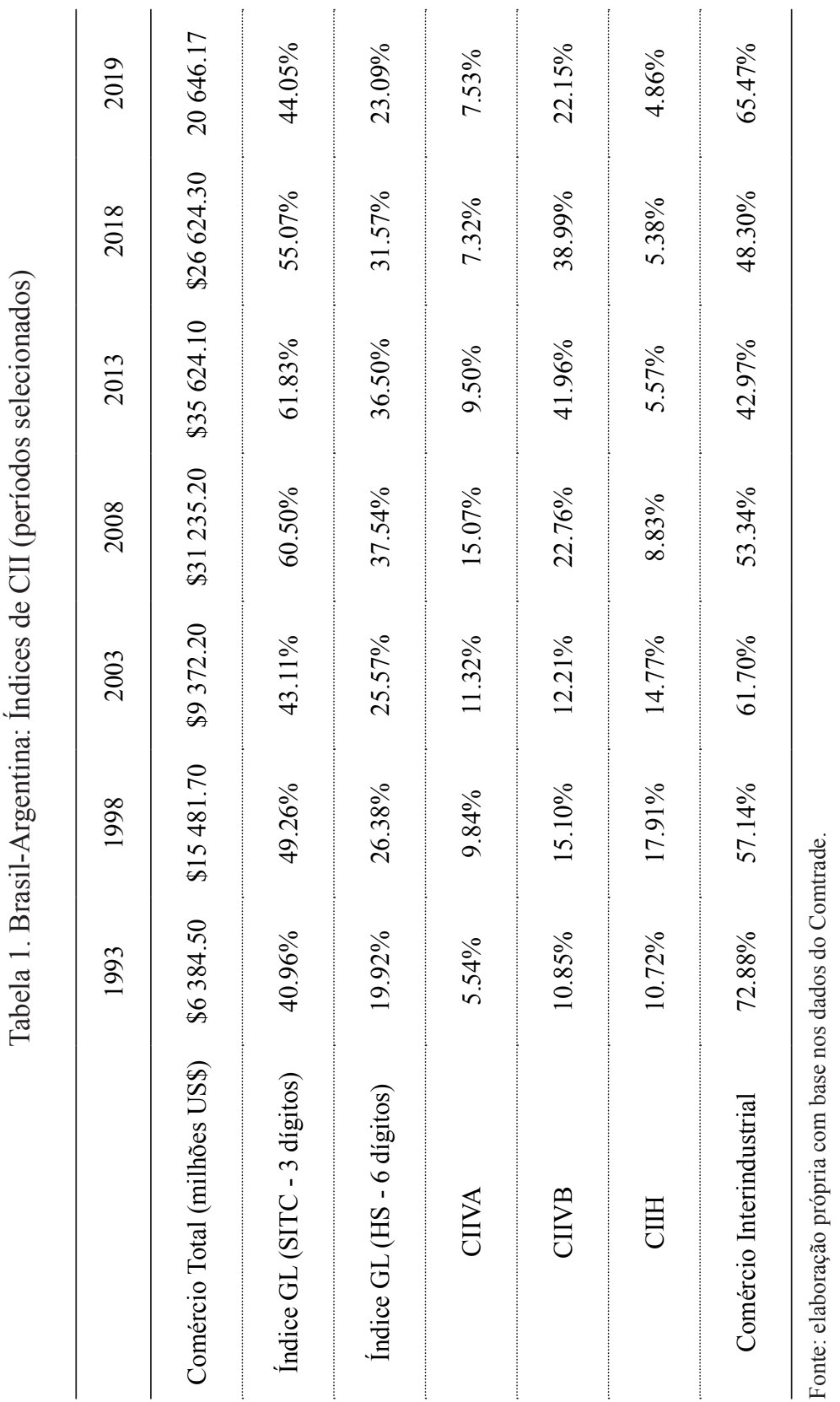


bilateral total. $\mathrm{O}$ aumento expressivo deste tipo de comércio apenas com o esforço inicial de desgravação das tarifas alfandegárias pode ter sido influenciado pela presença de outros determinantes do CII, como a proximidade geográfica, semelhanças culturais e de preferências econômicas e a presença de EMNs na região.

Os resultados de 2003 ainda refletem o período de turbulência econômica vivida pelos integrantes do Mercosul, especialmente pela Argentina, período que começou no final dos anos 1990. Desta forma, observou-se inclusive uma redução do valor do comércio em relação a 1998. Vale destacar que seus impactos econômicos não foram apenas quantitativos, situação em que os índices teriam se mantidos estáveis. Houve, de fato, uma reversão destes índices para todas as metodologias calculadas. A exceção é o fluxo CIIVA, mas o CII vertical total recuou em 1.42\%. Juntos, a reversão do comércio total e dos índices revelam um impacto significativo no padrão comercial entre estes países. Os valores do CII vertical e horizontal se reduziram respectivamente em US\$ 1.6 e US\$ 1.4 bilhão.

O período que começa em 2003 marca uma mudança de conjuntura no Mercosul, em função da chegada ao poder de presidentes ligados ao espectro político de esquerda no Brasil e na Argentina ${ }^{4}$, que questionaram o alinhamento aos Estados Unidos e a adoção de políticas econômicas ortodoxas. Desta forma, impulsionaram o Mercosul, ampliando sua agenda para além da liberalização comercial. O elemento da integração produtiva no bloco econômico surgiu concretamente a partir deste período com a criação do Fundo para a Convergência Estrutural (Focem) (2004), com o lançamento da Agenda de Implementação Consensuada (AIC) no âmbito da IIRSA e com a criação do GAHIP (Grupo Ad Hoc da Integração Produtiva) em 2007.

Para além destes instrumentos aplicados, um elemento que pode ter influenciado indiretamente o estreitamento das relações comerciais e produtivas no Mercosul foi a modificação do caráter da política externa brasileira a partir do início dos anos 2000, que objetivou fortalecer suas relações com os países em desenvolvimento, principalmente com aqueles do hemisfério sul, em detrimento do alinhamento com os países centrais, característico da política externa do Governo Fernando Henrique Cardoso (Lima, 2005; Vigevani \& Cepaluni, 2007). Neste ínterim, o Mercosul ocupou um lugar estratégico, pois se tornou um instrumento de negociação comercial com o resto do mundo e de inserção na economia global (Vigevani \& Mariano, 2005).

4 Luís Inácio Lula da Silva, do Partido dos Trabalhadores, e Néstor Carlos Kirchner, peronista do Partido Justicialista, assumiram ambos em 2003 as presidências do Brasil e da Argentina, respectivamente. 
As estimativas para o ano de 2008 refletem esta nova fase do Mercosul, que foi interrompida logo em seguida pela crise financeira internacional. O valor do comércio total se recuperou e foi significativamente maior que as cifras observadas em 1998. Além disso, a participação do CII voltou a representar quase metade do comércio total de acordo com a metodologia do índice FF.

Observou-se, também em 2008, um aumento significativo do comércio total ao mesmo tempo em que os índices de CII ganharam participação. Os fluxos desagregados de comércio mostram que o CII do tipo horizontal perdeu participação em benefício do CII do tipo vertical. De fato, em 2008 o CII do tipo horizontal apresentou a menor participação até então, e esta tendência se mantém nos anos seguintes. Esta é uma evidência importante de que, entre os anos 2000 e 2013, o comércio entre Brasil e Argentina se modificou qualitativamente, assumindo cada vez mais padrões típicos de países que participam de esquemas de integração produtiva.

Apesar da perda de participação do CII horizontal em 2008, o seu valor total foi maior em quase US\$ 1.4 bilhão comparado a 2003. De fato, houve uma intensificação do CII horizontal em termos absolutos, enquanto o CII vertical cresceu mais do que proporcionalmente, alcançando uma participação de $37.8 \%$ do comércio bilateral total.

Em 2013 ainda se observou certo crescimento comercial em relação a 2008. O mesmo pode ser dito com relação ao CII, que alcançou a participação de $57.03 \%$, de acordo com o índice FF. Os resultados revelam uma modificação qualitativa importante em 2013, quando se observou uma reorganização significativa dos fluxos de comércio entre Brasil e Argentina. A participação dos fluxos CIIVA, CIIH e comércio interindustrial se reduziram em benefício do CIIVB, que atingiu quase $42 \%$ do comércio bilateral total. Mais da metade do comércio bilateral nesse ano foi do tipo CII vertical.

Esta tendência se manteve em 2018, quando, apesar de o comércio total entre Brasil e Argentina ter diminuído em quase US\$ 10 bilhões, o CIIVB se manteve em níveis elevados. O CII vertical total representou $46.31 \%$ e a participação do comércio interindustrial aumentou em quase 5\%. Em 2019, no entanto, a reversão do CII se intensifica e a participação do CII vertical total se reduz a $27 \%$, maior apenas que os números observados em 1993.

É possível identificar três momentos distintos no período estudado. O primeiro se estende até o início dos anos 2000, quando a evolução do índice FF na relação bilateral entre Brasil e Argentina é mais quantitativa, resultado dos 
primeiros esforços de redução das barreiras comerciais no âmbito do Mercosul. A partir dos resultados de 2008, observa-se uma tendência de mudança qualitativa no padrão de comércio bilateral, que não só está cada vez mais relacionado com o CII, como também com um caráter mais vertical. Este padrão se acentua em 2013, mesmo num contexto de dificuldade econômica para todos os integrantes do Mercosul, quando o CII do tipo vertical representa $51.46 \%$ do comércio bilateral total. Como mencionado, estes números surgem no período de chegada de governos mais alinhados com o projeto de aprofundamento do Mercosul. Finalmente, o terceiro momento capturado pelos resultados de 2018 e 2019 representa o início de uma inflexão do padrão observado anteriormente, desta vez com reversão significativa da participação do CII. De fato, em 2015 e 2016 houve uma nova mudança de conjuntura política nos dois países estudados, com a chegada, desta vez, de políticos ligados ao espectro político de direita ${ }^{5}$, céticos quanto ao projeto da integração do Mercosul e mais interessados num modelo mais liberal.

Um exame mais detalhado da trajetória deste comércio bilateral, no nível da indústria a 3 dígitos de desagregação do SITC, revela-nos os setores econômicos que mais se destacaram nesta interação econômica. Com o objetivo de filtrar as indústrias com maior importância relativa no comércio total e no processo de integração produtiva, adotamos os critérios utilizados por Lucángeli (2007): (a) comércio bilateral maior que US\$ 10 milhões; (b) índice GL maior que 50\%.

Conforme pode ser observado na Tabela 2, de 1993 para 1998 o número de indústrias que satisfaziam os critérios mencionados saltou de 30 para 67 e se manteve neste patamar até se reduzir para $48 \mathrm{em} 2018$. Embora o número total tenha se mantido, houve variação importante das indústrias que satisfaziam os critérios de ano para ano. De 1998 para 2003, por exemplo, a composição de indústrias mudou em pelo menos um terço apesar de o número total ter se mantido praticamente inalterado. Isto é, vinte e uma indústrias que satisfaziam os critérios em 1998 não mais o faziam em 2003. Ao mesmo tempo, outras vinte que estavam ausentes em 1998 passaram a integrar, em 2003, o conjunto de indústrias com GL maior que $50 \%$ e comércio total maior que US\$ 10 milhões. Nos anos seguintes, a variação da composição é menor, mas se mantém em pouco mais de dez indústrias.

5 Em dezembro de 2015, Mauricio Macri assumiu a presidência da Argentina, e em 2016, Dilma Roussef (2011-2016) sofreu o processo de impeachment no Brasil, marcando a saída do PT (Partido dos Trabalhadores) do governo, que havia iniciado com Lula (2003-2010) em 2003. Nesse momento, Michel Temer assumiu o poder até final de 2018, quando foi sucedido pelo atual presidente Jair Bolsonaro. 
EVIDÊNCIAS DA INTEGRAÇÃO PRODUTIVA ENTRE BRASIL E ARGENTINA NO CONTEXTO...

Tabela 2. Brasil-Argentina: Indústrias com índice GL maior que 50\% e valor comercializado acima de US\$ 10 milhões

\begin{tabular}{|c|c|c|c|c|c|c|c|}
\hline & 1993 & 1998 & 2003 & 2008 & 2013 & 2018 & 2019 \\
\hline $\begin{array}{l}\text { Total de } \\
\text { Indústrias }\end{array}$ & 30 & 67 & 66 & 65 & 68 & 48 & 51 \\
\hline $\begin{array}{c}\text { Comércio } \\
\text { Total (em US\$ } \\
\text { bilhão) }\end{array}$ & 2.3 & 7.9 & 4.6 & 16.2 & 24.9 & 16.4 & 9.2 \\
\hline $\begin{array}{l}\text { Participação } \\
\text { Comércio } \\
\text { Bilateral Total }\end{array}$ & $36.37 \%$ & $51.22 \%$ & $49.37 \%$ & $52.13 \%$ & $69.94 \%$ & $60.39 \%$ & $44.92 \%$ \\
\hline $\begin{array}{c}\text { Top } 5 \\
\text { Indústrias* }\end{array}$ & $\begin{array}{c}784 \\
781 \\
713 \\
334 \\
782\end{array}$ & $\begin{array}{l}781 \\
782 \\
784 \\
713 \\
783\end{array}$ & $\begin{array}{l}781 \\
782 \\
784 \\
571 \\
713\end{array}$ & $\begin{array}{l}781 \\
782 \\
784 \\
571 \\
783\end{array}$ & $\begin{array}{l}781 \\
782 \\
784 \\
713 \\
334\end{array}$ & $\begin{array}{l}781 ; \\
782 ; \\
784 ; \\
571 ; \\
713\end{array}$ & $\begin{array}{l}781 \\
784 \\
625 \\
571 \\
713\end{array}$ \\
\hline
\end{tabular}

Fonte: elaboração própria com base nos dados do Comtrade.

Apesar da variação do valor comercializado nestas indústrias, entre 1998 e 2008 sua participação no comércio bilateral se manteve em torno de 50\%. Em seguida cresceu significativamente em 2013, quando representou quase $70 \%$ do comércio total e, em 2019, regrediu para níveis observados somente no início do período analisado.

As cinco indústrias com maior comércio bilateral, no entanto, são praticamente as mesmas ao longo de todo o período analisado. Ao todo são oito que variam entre si nos seis anos analisados. Seis (SITC 625, 713, 781, 782, 783, 784) destas indústrias são relacionadas com o setor automotivo, uma (SITC 334) se refere ao setor de petróleo e uma (SITC 571) ao setor de químicos.

Ao todo, 108 indústrias se revezaram ao longo do período analisado no conjunto daquelas com alto nível de comércio de duas vias e valor transacionado. Catorze delas estavam presentes em todos os anos, e outras doze em cinco anos. No extremo oposto, verificaram-se vinte e cinco indústrias que apareceram em apenas um dos seis anos estudados. A trajetória do comércio e do índice GL destas indústrias indicam 
alguns setores com potenciais esquemas de integração produtiva entre Brasil e Argentina. Destaca-se o grande setor de produtos químicos, como já tinha observado Lucángeli (2007), e, também, as indústrias têxtil, metalúrgica, de maquinário e a automotiva.

Em seguida analisaremos o comércio entre Brasil e Argentina de acordo com a sua classificação em estágios da produção a partir dos resultados do IRPC. Estamos interessados especialmente na trajetória dos fluxos de bens intermediários, que estão associados a esquemas de integração produtiva. Esta metodologia contribui com nossa investigação porque, em vários casos, as indústrias podem utilizar insumos e bens intermediários provenientes de outros ramos industriais, que não são capturados pelas estimativas de CII.

A Tabela 3 agrega o IRPC para a relação entre Brasil e Argentina nos mesmos períodos estudados com os índices de CII. Em termos gerais, observa-se que a participação de bens intermediários nas exportações brasileiras já era relevante em 1993. Na medida que o comércio cresce, no entanto, observa-se uma queda importante da participação deste tipo de produtos, principalmente de partes e componentes (III). O intercâmbio destes bens apresenta algum crescimento em termos proporcionais em 2008 e 2013, embora não ultrapasse o patamar observado ainda em 1993 (25.49\%), e logo volta a perder participação em 2018 e 2019. Portanto, não há uma tendência de crescimento sustentável das exportações deste tipo de bens em termos relativos. Vale dizer, no entanto, que, em termos absolutos, as exportações brasileiras de partes e componentes cresce entre os anos 2000 e 2013.

Os bens de consumo aparecem como principal conteúdo das exportações argentinas no período analisado, com a exceção de 2003, quando esta posição foi assumida pelos bens semiacabados. Assim como no caso brasileiro, a maior participação das exportações de partes e componentes da Argentina foi observada em 1993 (15.19\%) e ficou em torno de $10 \%$ até 2013, sem demonstrar uma tendência clara de crescimento. Pelo contrário, em 2018 e 2019 esta participação relativa diminui consideravelmente. O mesmo ocorre com os bens semiacabados, que após o máximo de $34.09 \%$ em 2003, alcançaram o mínimo de $18.69 \%$ em 2013, quando as exportações totais foram quase quatro vezes maiores. Os bens de capital, por outro lado, após uma queda importante em 2003, voltaram a ganhar participação nos demais períodos estudados.

O comércio de bens intermediários e de capital entre Brasil e Argentina representa parcelas importantes do comércio bilateral total ao longo de todo o período. De fato, já em 1993 eles explicavam mais de 70\% das exportações brasileiras. Em 1993 e 1998 estes três fluxos respondiam por cerca de 40\% das exportações 


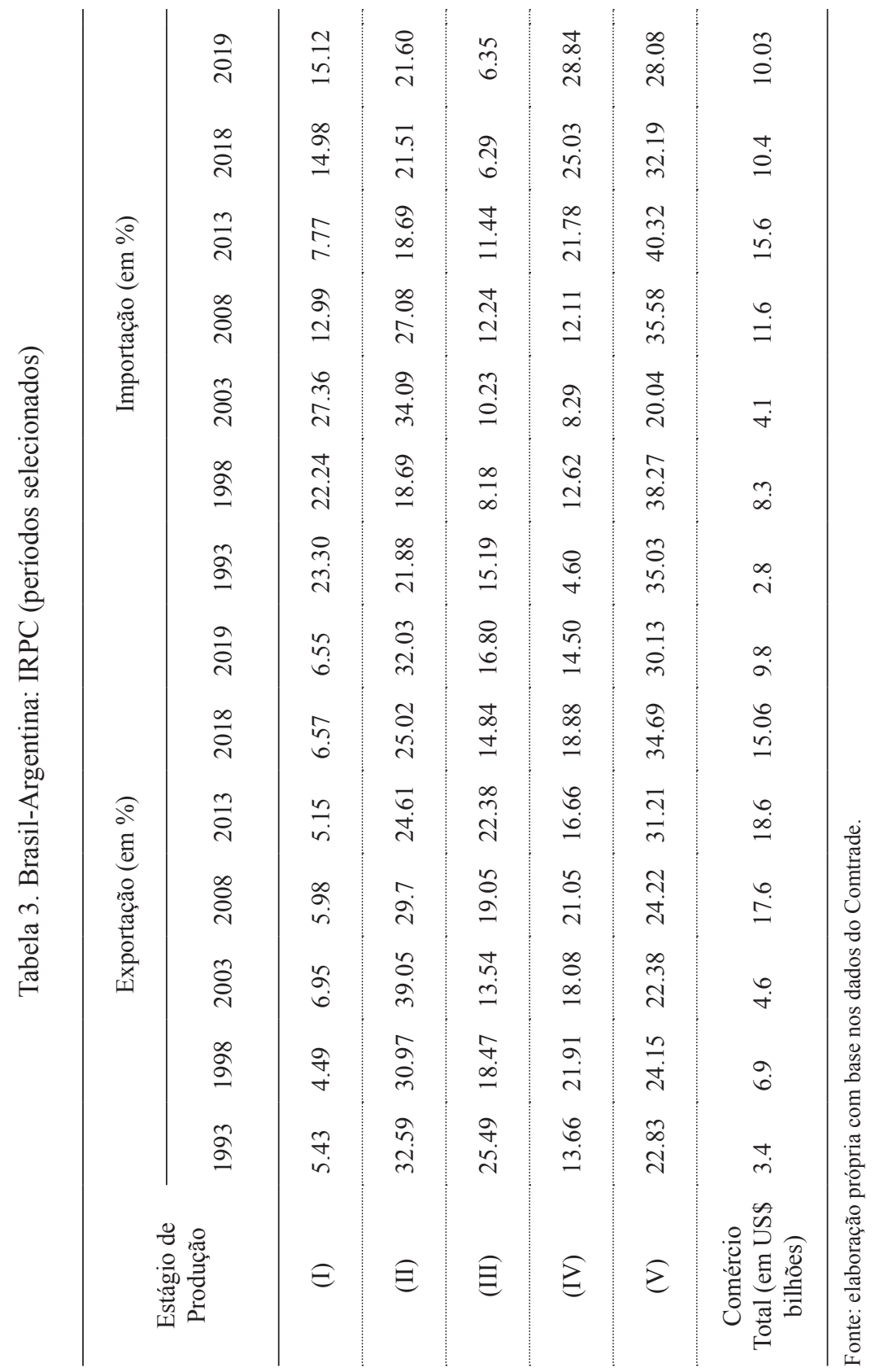


argentinas e subiram para $50 \%$ nos anos 2000 . Aliado ao crescimento do valor comercializado, estes dados indicam que o intercâmbio destes produtos cresceu significativamente no período, em termos absolutos.

A importância relativa dos bens intermediários no comércio entre Brasil e Argentina sugere que há uma relação produtiva, além de comercial, relevante entre eles. No entanto, é necessário ter cautela com relação à análise dos bens semiacabados (II), que constituem a maior parte do intercâmbio de bens intermediários em todos os anos, pois, como alertou Flôres Junior (2010) ao analisar o IRPC do Mercosul no início dos anos 2000, a maior parte do intercâmbio de bens semiacabados são basicamente commodities e recursos naturais rudemente elaborados e que, portanto, não constituem indícios de integração produtiva. Por esta razão a maior parte dos estudos considera apenas a parcela do comércio de partes e componentes (III).De fato, ao longo de todos os anos estudados, observa-se que os produtos semiacabados mais relevantes, em valor de comércio, são mesmo relacionados a commodities e recursos naturais. No caso das exportações brasileiras, entre os dez mais importantes destacam-se óxido de alumínio (SITC 2852), produtos laminados de ferro (SITC 67413), fio de cobre refinado (SITC 68241), entre outros. As principais exportações argentinas de bens semiacabados contemplam produtos relacionados ao setor de alimentos e animais vivos, como farinha de trigo (SITC 0461) e malte (SITC 0482), mas também combustíveis como gás propano (SITC 3421), gás butano (SITC 3425), hidrocarbonetos gasosos (SITC 3442), entre outros.

Por outro lado, neste grupo dos principais produtos semiacabados, também aparecem alguns relacionados aos setores identificados a partir dos índices de CII, notadamente o de químicos e plásticos. Na pauta de exportação brasileira se destacam, por exemplo, duas variedades de polietileno (SITC 57111 e 57112) e polipropileno (SITC 57511); enquanto entre as exportações argentinas, polímeros de etileno em formas primárias (SITC 5719), polietileno (SITC 57112) e cloreto de polivinila (SITC 57311) estão entre os produtos semiacabados com maior valor comercializado.

O Gráfico 1 ilustra a trajetória do valor comercializado dos produtos intermediários relacionados aos setores identificados como propensos a processos de integração produtiva entre Brasil e Argentina. Após um crescimento do comércio bilateral observado em todos os setores em 1998, todos recuaram em 2003, com a exceção do setor de químicos. A trajetória dos anos 2000 também é muito semelhante entre eles, quando se observa um forte crescimento até 2008. Em 2013 as trajetórias se dividem: o setor de maquinário e automotivo continuam crescendo; enquanto o de químicos e metais já mostram um certo arrefecimento. Vale destacar que, já em 1998, o comércio de bens intermediários do setor de químicos é maior 
que o do automotivo. Isto continua verdade até 2019, com a exceção do valor registrado em 2013. O setor têxtil apresenta um desenvolvimento relativo menor que as demais indústrias, com fraco crescimento comercial mesmo em 1998 e 2008.

Em termos proporcionais, o setor de produtos químicos agregado (seção SITC 5 completa), que inclui a produção de plástico e outros bens, representa em média $38 \%$ do comércio bilateral de bens semiacabados em todo o período analisado. Em 2003, quando o comércio caiu consideravelmente, esta proporção subiu para $46.47 \%$, indicando que há uma robustez no intercâmbio destes bens. Cerca de $59 \%$ do comércio bilateral de partes e componentes se referem aos produtos do setor automotivo. A participação máxima de $63.73 \%$ foi observada em 2013. Os bens semiacabados relacionados a metais apresentavam uma participação média de $14 \%$ do comércio de bens semiacabados até 2003 . Este patamar subiu para $24.63 \%$ em 2018 . O comércio de maquinários e equipamentos teve suas maiores participações no intercâmbio de partes e componentes em 1998 e 2003, respectivamente, $43.93 \%$ e $44.42 \%$. A média dos períodos seguintes caiu para $37 \%$. Finalmente, o comércio de bens semiacabados do setor têxtil tem sua maior participação em 1998, em 10.74\%, mas registra quedas sistemáticas em todos os anos seguintes, até registrar apenas 4.49\% em 2018.

Gráfico 1. Intercâmbio entre Brasil e Argentina de produtos intermediários selecionados (1993-2019)

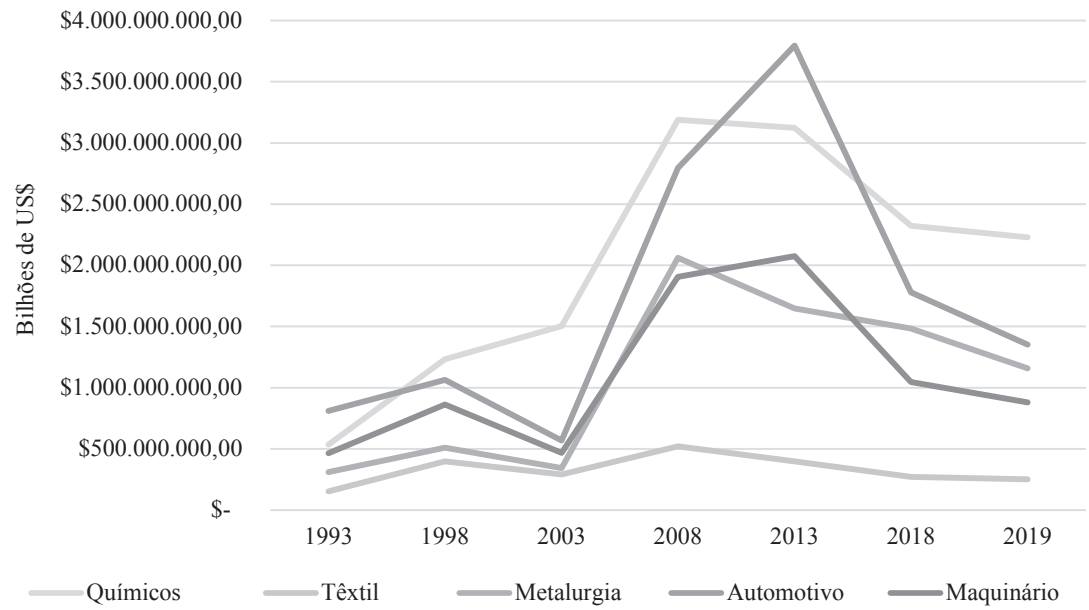

Fonte: elaboração própria com base nos dados do Comtrade. 
Em suma, os dados indicam que há uma incidência importante de bens intermediários no comércio entre Brasil e Argentina, principalmente em 1993, quando não havia tanta interferência dos desdobramentos positivos da integração regional. No entanto, apesar de se observar um crescimento significativo em termos absolutos a partir de 2003, não há uma tendência clara de ganhos de participação destes produtos ao longo do tempo.

\section{CONSIDERAÇÕES FINAIS}

De uma maneira geral, vimos na quarta seção que o CII apresentou significativo crescimento relativo e absoluto principalmente a partir dos anos 2000 . No entanto, esta tendência sofreu uma inflexão nos últimos períodos observados. Os resultados do IRPC, por outro lado, foram menos animadores no que se refere aos fluxos de partes e componentes. De fato, os números em 2008 e 2013 demonstram avanços em relação a 2003, mas não superam os patamares dos anos 1990 e logo recuam em 2018 e 2019. Desta forma, não foi observado um crescimento sustentável do comércio destes produtos, o que representaria um indício importante de uma fragmentação regional da produção. No que se refere aos bens semiacabados, apesar de o seu intercâmbio ser relevante durante todo o período, inclusive nos primeiros anos de existência do Mercosul, parte importante destes produtos se refere apenas a derivados de bens primários levemente elaborados.

Nossas evidências revelam crescimento limitado e movimentos instáveis dos indicadores de integração produtiva ao longo do período analisado. Além das retrações derivadas das crises econômicas, os resultados foram impactados também pela mudança de ênfase, por parte dos governos nacionais, e orientação da integração regional. Na primeira parte dos anos 2000, observou-se uma gestão do Mercosul voltada para formulação de políticas e incentivos à integração produtiva, e com governos nacionais comprometidos no discurso com este projeto. Como resultado, entrou em marcha um padrão de intensificação da integração produtiva, medida em termos de ganhos de participação do CII e do IRPC em 2008 e 2013. No entanto, este padrão foi revertido com a mudança de conjuntura política regional em 2016, conforme se observa nos resultados de 2018 e 2019. Estes números sugerem que a contribuição de uma integração regional na promoção da integração produtiva será maior à medida que mais eficientes e sustentadas forem as políticas ativas voltadas para esse objetivo.

A falta de consistência da trajetória de integração produtiva pode estar relacionada com o caráter da integração regional do Mercosul, que apesar de sugerir 
uma integração mais profunda, iniciou-se com uma proposta objetiva de expandir o comércio entre seus membros a partir da redução das barreiras comerciais. Nos anos 2000, apesar do aumento de ênfase ao bloco econômico a partir da chegada ao poder concomitantemente de governos mais progressistas ${ }^{6}$ no Brasil, Uruguai e Argentina, o foco no Mercosul ficou em grande parte apenas no discurso (Medeiros \& Dri, 2013). As políticas de integração produtiva deste período significaram um avanço importante, mas foram limitadas e o bloco econômico se manteve com baixa institucionalidade, que representou clara resistência ao seu aprofundamento. Desta forma, a nova mudança de orientação política dos governos nacionais, a partir de 2016, pôde rapidamente reverter a tendência anterior.

Neste ínterim, os integrantes do Mercosul ignoraram a ideia de estabelecer relações com outros países de forma conjunta, com maior poder de barganha, e buscaram unilateralmente diversificar suas relações comerciais com o resto do mundo. A aproximação do Brasil com os demais integrantes do BRICS é um exemplo claro disto, mas movimentos semelhantes foram adotados também pelos outros membros (Vigevani \& Cepaluni, 2007).

Este comportamento está de acordo com o argumento de Garzón (2017) sobre o sistema multipolar decentralizado da atualidade. De acordo com o autor, o sistema internacional moderno, aliado ao nível do desenvolvimento das tecnologias de comunicação e transporte, permite que países de qualquer parte do planeta se relacionem política e economicamente com potências regionais diversas, criando assim um alto custo de oportunidade sobre o desenvolvimento de integrações regionais mais profundas, que requerem transferência de soberania nacional para a instituição regional (Hancock, 2009). No caso do Mercosul, a relutância dos membros em decidir sobre o dilema do seu aprofundamento significou um estado de inércia institucional que perpetuou pendências básicas de qualquer integração regional, como o próprio acordo de livre comércio, a consolidação da TEC, entre outros esforços de coordenação política e econômica.

Finalmente, os resultados limitados de integração produtiva entre Brasil e Argentina expostos neste trabalho nos permitem refletir sobre o modelo de integração do Mercosul. Atualmente, ele se mantém como uma versão incompleta de união aduaneira. No entanto, a busca de uma reestruturação da atividade produtiva regional capaz de garantir uma maior geração de valor adicionado e melhores con-

6 Já mencionamos os presidentes Lula e Nestor Kirchner no Brasil e Argentina respectivamente. Cabe mencionar ainda o caso do presidente uruguaio Tabaré Vázques, da Frente Amplio, que assumiu em 2005 e seu sucessor, José Mujica, a partir de 2010. 
dições de inserção nos mercados internacionais exige um modelo mais profundo de integração, com instituições supranacionais, e alta capacidade de coordenação política entre os membros. Se o custo de oportunidade deste projeto é muito alto, como sustenta Garzón (2017), então a alternativa é que os membros dialoguem e revejam as perspectivas desta integração regional no sentido de construir um modelo que não constranja sua autonomia internacional e não impeça seus planos individuais. Porém, é importante destacar que esta opção representa um retrocesso sobre os ideais de uma integração voltada para o desenvolvimento econômico conjunto e de uma inserção mais equilibrada na economia internacional. Os resultados de 2018 e 2019 já ilustram este ponto. Com Governos mais céticos quanto ao projeto do Mercosul, se observou forte redução do comércio bilateral e reversão dos indicadores de integração produtiva.

\section{REFERÊNCIA BIBLIOGRÁFICA}

Angelis, J., \& Porta, F. (2014). Condições para a Integração Produtiva no Mercosul: uma análise a partir do estudo dos fluxos de comércio bilaterais. En W. Desiderá Neto, \& R. Teixeira, R. (Org.). Perspectivas para a Integração da América Latina (pp. 65-92). Brasília: IPEA/CAF.

Baldwin, R. (2012). Global supply chains: why they emerged, why they matter, where they aregoing. (CEPR, Working Paper FGI-2012-1).

Bandeira, L. A. M. (2010). Argentina e Estados Unidos: conflito e integração na América do Sul (da Tríplice Aliança ao Mercosul). Rio de Janeiro: Civilização Brasileira.

Bembi, M., Angelis, J. de, \& Molinari, A. (2012). Algunas mediciones de integración productiva en el Mercosur. Trabajo presentado en XLVII Reunión Anual de la Asociación Argentina de Economía Política (pp. 1-39). Universidad Nacional de la Patagonia San Juan Bosco, Trelew, Chubut.

Brasil, R. F. Do \& Argentina, R. (1986). Ata para a Integração Brasileiro - Argentina.

Carneiro, F. (2015). Fragmentação internacional da produção e cadeias globais de valor. (IPEA, Texto para Discussão No. 2097).

Comissão Econômica para a América Latina e o Caribe [CEPAL] (2000a). O mercado comum latino-americano. En R. Bielschowsky (Org.). Cinquenta anos de pensamento na CEPAL, 1, 347-372. Rio de Janeiro, São Pablo: Editora Record.

Comissão Econômica para a América Latina e o Caribe [CEPAL] (2000b). O Regionalismo aberto na América Latina e no Caribe: a integração econômica a serviço da transformação produtiva com equidade. En R. Bielschowsky (Org.). Cinquenta anos de pensamento na CEPAL (Vol. 2, pp. 937-958). Rio de Janeiro, São Pablo: Editora Record. 
Chesnais, F. (1996). A mundialização do capital. São Paulo: Ed. Xamã.

Chesnais, F. (2013). Present international patterns of foreign direct investment: underlyingcauses and some policy implications for Brazil. Revista de Economia Contemporânea, 17(3), 376-422.

Ferrer, A. (2006). Hechos y ficciones de la globalización: Argentina y el Mercosuren el sistema internacional. Buenos Aires: Fondo de Cultura Económica.

Findlay, R., \& O'rourke, K. (2007). Power and Plenty: trade, war, and the World Economy in the Second Millenium. New Jersey: Princeton University Press.

Flôres Junior, R. (2010). A Fragmentação Mundial da Produção e Comercialização: conceitos e questões básicas. En R. Alvarez, R. Baumann, \& M. Wohlers (Org.). Integração Produtiva: caminhos para o Mercosul (pp. 56-115). Brasília: Agência Brasileira de Desenvolvimento Industrial.

Fontagné, L., \& Freudenberg, M. (1997). Intra-industry trade: Methodological issues reconsidered. (CEPII, Document de Travail No. 97-01).

Garzón, J. F. (2017). Multipolarity and the future of economic regionalism. International Theory, 9(1), 101-135. doi:10.1017/S1752971916000191

Grubel, H., \& Lloyd, P. (1975). Intra-industry trade: The theory and measurement of international trade in differentiated products. New York: John Wiley.

Hancock, K. (2009). Regional integration: choosing plutocracy. New York: Springer.

Krugman, P. (1979). Increasing Returns, Monopolistic Competition, and International Trade. Journal of International Economics, 9, pp. 469-479. Disponível em https://pr.princeton.edu/pictures/g-k/krugman/krugman-increasing_returns_1978.pdf

Lancaster, K. (1979). Variety, Equity and Efficiency. New York: Columbia University Press.

Lemoine, F., \& Ünal-Kesenci, D. (2004). Assembly trade and technology transfer: the case of China. World Development, 32(5), pp. 829-850.

Lima, M. R. S. d. (2005). A política externa brasileira e os desafios da cooperação Sul-Sul. Revista brasileira de política internacional, 48 (1), 24-59.

Lucángeli, J. (2007). La Especialización Intraindustrial en Mercosur. (CEPAL Serie Macroeconomía del Desarrollo No. 64).

Machado, J. (2010). Integração Produtiva: referencial analítico, experiência europeia e lições para o Mercosul. En R. Alvarez, R. Baumann, \& Wohlers, M. (Org.). Integração Produtiva: caminhos para o Mercosul. (pp. 116-155). Brasília: Agência Brasileira de Desenvolvimento Industrial. Disponível em https:// repositorio.cepal.org/bitstream/handle/11362/5431/1/S0701103_es.pdf

Mansfield, E. D. ,\& Milner, H. V. (1999). The New Wave of Regionalism. International Organization, 53(3), 589-627.

Medeiros, M., \& Dri, C. F. (2013). Which brazilian policy for regionalism? discourse and institutional development in Mercosur. Estudios internac- 
ionales (Santiago), 45(175), 41-61. doi: http://dx.doi.org/10.5354/07193769.2013.27371

Mercado Comum do Sul [MERCOSUL] (1991). Tratado para a Constituição de um Mercado Comum entre a República Argentina, a República Federativa do Brasil, a República do Paraguai e a República Oriental do Uruguai - Tratado de Assunção.

Milberg, W., \& Winkler, D. (2013). Outsourcing Economics: global value chains incapitalista development. Cambridge: Cambridge University Press.

Nonnenberg, M. (2013). Integração produtiva, fragmentação da produção e evolução do comércio internacional: como evoluíram os países da Ásia e América Latina? (IPEA, Texto para Discussão No. 1905).

Organização para Cooperação e Desenvolvimento Econômico [OCDE]. (2002). OECD Economic Outlook. [S.1.]: United Nations.

Ohlin, B. (1933). Interregional and International trade. Cambridge: Harvard University Press.

Park, A., Nayyar, G., \& Low, P. (2013). Supply chain perspectives and issues: a literature review. Hong Kong: Fung Global Institute.

Ricardo, D. (1996). Princípios de Economia Política e Tributação. São Paulo: Ed. Nova Cultural.

Vigevani, T. \& Cepaluni, G. (2007). A Política Externa de Lula da Silva: a estratégia da autonomia pela diversificação. Contexto Internacional, 29(2), 273335. doi: https://doi.org/10.1590/S0102-85292007000200002

Vigevani, T. \& Mariano, M. (2005). A ALCA e a Política Externa Brasileira. (Cadernos CEDEC, No. 74). Disponível em http://www.cedec.org.br/files_pdf/ CAD74.pdf

Vigevani, T.,Mariano, K. P. \& Mariano, M. P. (2001). Brasil e Integração Regional: Mercosul and Alca. (Cadernos CEDEC, No. 70). Disponível em http://www. cedec.org.br/files_pdf/CAD70.pdf

Yeats, A. (1998). Just How Big is Global Production Sharing? (World Bank Policy Research, Working Paper No. 1871).

(C) 2022 por los autores; licencia no exclusiva otorgada a la revista Estudios económicos. Este artículo es de acceso abierto y distribuido bajo los términos y condiciones de una licencia Atribución-No Comercial 4.0 Internacional (CC BY-NC 4.0) de Creative Commons. Para ver una copia de esta licencia, visite http://creativecommons.org/licenses/by-nc/4.0 